weak. When the doctor injected the dye into a vein in my hand he couldn't find one at first and it hurt me when he did. The staff in this department weren't as sympathetic as all the others and did not tell me beforehand what they were going to do. I had a good cry when I got back to my room.

The consultants decided that I would have to have my thymus gland and $90 \%$ of my thyroid gland removed. When I was told it sounded drastic but the surgeon told me that while he was removing the thymus it would be advisable to remove the thyroid at the same time. The operation was carried out successfully and after a short stay in intensive care I returned to the ward for the usual postoperative care. After the drains were removed from my neck I was allowed home, taking with me a lot of tablets, and left to convalesce slowly in my own surroundings.

\section{Need for understanding}

I have written down my experiences primarily to help my convalescence but also to point out that patients need to have understanding and sympathy as well as medical and surgical care. They need to be involved in their treatment and not talked over. You are ill, but not stupid and you can accept what has to be done to you if you have it explained first. I was lucky because my consultants were considerate to my feelings and nearly all those I came into contact with at the hospital were kind caring people. I found this a great comfort because there were times when I felt really ill and depressed.

The star on top of my Christmas tree will now always belong to the wonderful staff of the intensive care unit and the crash team who saved my life on that black Monday in what should have been the festive season.

\title{
My "one in a million" chance
}

\section{Rosemary McCann}

On 8 January 1989 I was on the return leg of my regular fortnightly flight from London to Belfast: such are the trials of a long distance romance. The departure was delayed, but that did not worry me. I was preoccupied with my new year's resolution-completing two projects for a forthcoming exam.

At the check in I was allocated seat 12C. "Great, more leg room and space to work," I thought. A girl was in my seat when I got on the plane and I asked her to move. The lady beside me chatted and we joked when a steward told her friend, sitting beside the emergency door, to familiarise herself with the emergency procedure for opening it.

Ten minutes into the flight, just after the meals were given out, a sudden banging started in the engine beside us. Sparks and flames flew out and the whole plane shuddered. The cabin crew dashed up to the cockpit and just as suddenly as the banging had started it stopped and the sparks disappeared. Nobody on the plane spoke - the only noise was someone weeping in the seat behind.

The Lockerbie air disaster, which had happened so recently, was foremost in my mind; perhaps there was a bomb on board this plane too. The captain told us that we were diverting to East Midlands Airport because of engine trouble. Everything seemed normal again and I remember dismissing the whole episode as a nuisance. It was only on our final approach to the airport that the same engine began to shudder and spit out flames . . . the aircraft was jumping like a car stalling. Petrified, I grabbed the hand of the lady beside me and prayed.

The plane was in absolute silence, no one screamed or shouted. "This is it, how many people survive an air crash," I thought, tasting the fear of a death with no one I loved near me.

\section{Perhaps it was a nightmare}

That is all I remember until I awoke to hear someone shrieking in pain. I thought perhaps I was at home in bed and was waking from a nightmare. Then the kind, plump face of an ambulanceman appeared and he told me that I was all right. My mind struggled to put together what had happened. It finally hit me that my last memory was of being on the plane. On the journey to hospital, the Queen's Medical Centre in Nottingham, I drifted in and out of consciousness. Coming round in casualty, I cautiously felt my way

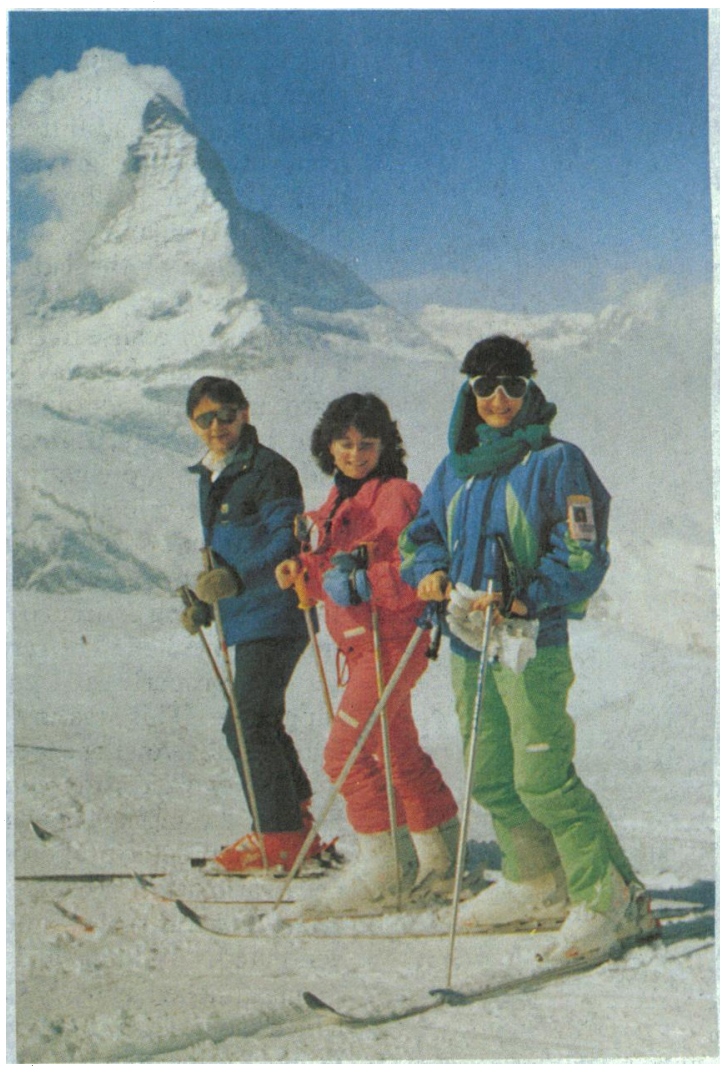

Dr McCann (right) skiing 18 months after the accident

round my body. I could not move my right leg and there was liquid pouring down my nose. It felt too watery for blood and I panicked, thinking that it was cerebrospinal fluid and that no one realised I had a fractured skull. Was I going to die?

When they transferred me to a bed the pain hit me and I never knew I could scream so loudly, yet as they cut off my clothes I was able to think my mother would have been proud that all my underclothes were new. There was an appreciation of various tubes being inserted and an awareness of an old man coming back and forth to feel my stomach. I could hear his voice but could not see his face. Eventually he said to somebody, "She is stable now." It was only then that I began to believe I was not going to die. I could not work out why this older man was treating me-it should have been 
young doctors, I thought-but later someone told me that all the survivors were treated by consultants.

A bishop and a priest appeared at my bedside and offered to contact my family to say that I was alive. I craved the contact of someone I knew beside me. A few hours later a nurse said that my husband had arrived. I giggled, wondering if I'd had such a bump on the head that I'd forgotten getting married. It turned out to be my brother followed by my boyfriend. After all that had happened I had only one thing on my mind: "I didn't let them cut my hair when they were stitching my head," I kept saying to him.

I had a fractured right ilium and a pin and plate were inserted four days later. Before the operation any movement was agony so that I worried the whole day of the operation about the journey to the theatre. Being anaesthetised in my own bed was a great relief - had I known that I would have had a happier day. Even though I was in pain I was happy to be alive as 37 people had been killed instantly.

I was aware of the daily television bulletins about the crash but was unable to assimilate all the information. We were treated as special patients. Mountains of flowers arrived every day, the nurses and doctors gave us gentle care and attention, and we saw a constant flow of dignitaries. Although I was protected from the media attention, my family was not so lucky. Kenneth Clarke told me that I had used up my one in a million chance: little did he know that this student of epidemiology quickly calculated that the risk remained the same. The Nottingham people's generosity can never be repaid. Restaurants sent food for the relatives and free refreshments were provided day and night.

\section{Everyone sported a black eye}

The air crash survivors were recognisable by their black eyes-everyone sported them. One man was even nicknamed "Mr Panda." In the six bedded section where I was three survivors were placed among old ladies suffering from fractured hips. One talked incessantly day and night, which drove us all crazy. Within a week I was given a single room where I stayed for four weeks. The survivors became close, helping each other along the road to recovery, praising each other's achievements. Relatives made a daily round of all the injured.

It took me a week to lift my head high enough to see the girl beside me and four weeks to see out of the window. I had always scoffed and underestimated the discomfort of constipation, but I got to know all about it. I was given Fybogel, which tasted revolting and solidified as I tried to suck it up through a straw. This was followed by lactulose, senna, etc, and ended with the dreaded Picolax. Many sachets of the foul tasting medicine were found after my departure, secreted under pillows, books, and even the television set. Relief from constipation came only seven weeks later when I was back on my feet.

I cannot praise the nursing staff enough. They were kind, gentle, and tried to joke me into eating. In the six weeks I spent in Nottingham my weight fell by $12.5 \mathrm{~kg}$ to $40 \mathrm{~kg}$.

In mid-February I was transferred to the Royal Victoria Hospital, Belfast. I weighed up all the pros and cons of the flight and considered train, bus, ferry any other modes of transport. But my inability to sit meant that I had to travel in a small plane with no toilet. Imagine what it is like being suspended over a papier maché bedpan on an aeroplane seat at $1000 \mathrm{~m}$ with a bladder up to your umbilicus and not be able to use it despite the sea view.

One morning after a particularly painful subcutaneous injection I had tears in my eyes and the sister asked if I was all right. Despite my reassurance that all was well the consultant arrived half an hour later and questioned me about sleeping patterns. I quickly realised what was happening and told him that I was sleeping well even though I was being turned every hour due to a bedsore. I had no desire to see a psychiatrist.

I was discharged home exactly eight weeks after the crash and my mother took on the role of constant carer. Although she had a good knowledge of the health service, she found it difficult to get the special bed, wheelchair, and bath seat that I needed. She had to contact a different agency for each of them. I had never appreciated the physical difficulties of getting around in a wheelchair. Kerbs were usually too high and difficult to negotiate and the wheels always stuck in gutters. Older people either stared or talked to the person pushing me. In one shop I handed my money to the cashier and she gave the change to my sister. "Is she all right?" she asked, as I sat there, my brain perfectly in tune.

\section{Trauma of research and compensation claims}

Survivors of any plane crash are unusual and are therefore the subject of an epidemic of research, but it is traumatic for survivors to relive the experience. It is difficult for them to refuse to cooperate in research for two reasons. Firstly, many see the interview or examination as benefiting them as a patient. Secondly, they worry that if they do not cooperate their compensation claim will be affected.

Being drawn into a major compensation claim is a frustrating, almost cheapening experience when individual rights, families' needs, and personal dignity are easily lost sight of. I had to attend a psychiatrist and I strongly resented intimate details of my personal life going down on three A4 sheets. It felt like trading my body in for money. The question of informed consent never arose. The wrangle for compensation continues and some people are in dire financial straits, having lost the family's breadwinner. I resent people telling me that I will be worth money because of this crash. I would willingly have foregone the fear of dying, lying in pain for months, and learning to walk again.

I would now like to be left alone to get on with my life. I recognise the classic stages that I went through after the crash: initial euphoria, grief, then guilt at having survived while others died. I am well but I am not yet physically fit. I am eternally grateful to the hospital staff; their medical, surgical, and nursing skills were of the highest calibre.

I still face an intense fear of flying, and having spoken to other survivors I realise that I am not alone in this terror. Every bump or noise or voice over the loudspeaker is translated into a possible problem. But living on an island it is impossible to avoid flying, and I mourn that loss of confidence.

Looking back I realise that perhaps some things could have been done better. Communications were not good on the night of the crash. Many people who rang the emergency number, especially from Northern Ireland, got an engaged tone. It was five and a half hours before the hospital gave out information. My relatives were lucky in that they knew four hours after the crash that I was alive, but many had to wait much longer.

In two of the other hospitals to which survivors were taken it was possible for them to be kept together where they could share information and emotions. Grieving relatives also want information. Their perceptions of events leading up to the crash were usually horrific and completely wrong, and it has helped them to talk to survivors. Perhaps it is the job of professional counsellors not only to operate on a one to one basis but to bring both these groups together. 